\title{
Follicle Stimulating Hormone Inhibits the Expression of p53 Up- Regulated Modulator of Apoptosis Induced by Reactive Oxygen Species Through PI3K/Akt in Mouse Granulosa Cells
}

\author{
Xiaoyan SHI ${ }^{1,2}$, Zhiqiang GUAN ${ }^{2}$, Jianning $\mathrm{YU}^{3}$, Honglin $\mathrm{LIU}^{2}$ \\ ${ }^{1}$ School of Pharmacy, Jiangsu Food and Pharmaceutical Science College, Huaian, China, ${ }^{2}$ College \\ of Animal Science and Technology, Nanjing Agricultural University, Nanjing, China, ${ }^{3}$ Laboratory \\ of Animal Improvement and Reproduction, Institute of Animal Science, Jiangsu Academy of \\ Agricultural Sciences, Nanjing, China.
}

Received December 16, 2019

Accepted April 22, 2020

Epub Ahead of Print June 25, 2020

\begin{abstract}
Summary
In mammalian ovaries, follicular atresia occurs periodically and destroys almost all the follicles in the ovary. Follicle-stimulating hormone (FSH) acts as the primary survival factor during follicular atresia by preventing apoptosis in granulosa cells (GCs). Many studies have demonstrated that oxidative stress-induced apoptosis is a main cause of follicular atresia. Reactive oxygen species (ROS)-induced GCs apoptosis is regulated by a variety of signaling pathways involving numerous genes and transcription factors. Therefore, we examined whether FSH inhibits the expression of p53 up-regulated modulator of apoptosis (PUMA) induced by reactive oxygen species (ROS) through phosphoinositide 3-kinase (PI3K) / protein kinase B (AKT) in mouse GCs. In vivo study: thirty-two-mice were randomly assigned to four groups and given FSH. We found that FSH can inhibit the 3-nitropropionic acid (3-NP) induced apoptosis and PUMA expression in mRNA level. Moreover, in vitro experiment, we found that $\mathrm{FSH}$ can inhibit the $\mathrm{H}_{2} \mathrm{O}_{2}$-induced apoptosis and PUMA expression in mRNA level. Additionally, we also found that PI3K/AKT inhibitor LY294002 abolished the downregulation of PUMA mRNA by FSH in vitro. In conclusion, FSH inhibit the expression of PUMA induced by ROS through PI3K/AKT pathway in vivo and vitro.
\end{abstract}

\section{Key words}

Follicle stimulating hormone - Oxidative stress - PI3K/AKT • Granulosa cells

\section{Corresponding author}

H.L. Liu, College of Animal Science and Technology, Nanjing Agricultural University, Weigang 1, Nanjing 210095, China. Email: liuhonglin@njau.edu.cn

\section{Introduction}

More than $99 \%$ of the mammalian ovarian follicles undergo degeneration during growth and development, a phenomenon called as follicular atresia (Asselin et al., 2000). Previous studies have demonstrated that follicular atresia is associated with granulosa cells (GCs) apoptosis, where DNA fragmentation, upregulation of pro-apoptotic gene expression and activation of caspases are observed (Jiang et al. 2003). Apoptosis can be induced by extrinsic as well as intrinsic factors in response to oxidative stress and damage (Valdez et al. 2005). Members of the B cell lymphoma 2 (Bcl-2) gene family have a central role in regulating programmed cell death by controlling pro-apoptotic and anti-apoptotic intracellular signals. Studies have suggested a close association between Bcl-2 family proteins and GCs apoptosis (Yang et al. 2017, Chowdhury et al. 2013). p53-upregulated modulator of apoptosis (PUMA) was originally identified as a BH3-only Bcl-2 subfamily protein. PUMA exerts its pro-apoptotic functions by inserting its $\mathrm{BH}-3$ domain into the hydrophobic pocket created by folding the $\mathrm{BH} 1, \mathrm{BH} 2$, and $\mathrm{BH} 3$ domains of anti-apoptotic Bcl-2 family members. This insertion relieves the inhibitory effect of anti-apoptotic Bcl-2 family members on Bax and/or Bak7, and promotes apoptosis (Roychoudhury et al. 2016).

Reactive oxygen species (ROS) are short-lived and highly reactive molecules. The generation of ROS in 
cells exists in equilibrium with a variety of antioxidant defences. At low to modest doses, ROS are considered to be essential for regulation of normal physiological functions involved in development such as cell cycle progression and proliferation, differentiation, migration and cell death. ROS also play an important role in the immune system, maintenance of the redox balance and have been implicated in activation of various cellular signalling pathways (such as PI3K/AKT signalling pathways). Excess cellular levels of ROS cause damage to proteins, nucleic acids, lipids, membranes and organelles, which can lead to activation of cell death processes such as apoptosis. Apoptosis is a highly regulated process that is essential for the development and survival of multicellular organisms. Oxidative stress is a critical factor in follicular atresia (Shen $\mathrm{M}$ et al. 2000)). Inhibition of ROS-induced GCs apoptosis will prevent abnormal follicular atresia, which can be used as a therapeutic tool to alleviate reproductive failure to improve the economy of production efficiency. Therefore, elucidating mechanisms of GCs apoptosis is vital for the development of new drugs that inhibit GCs apoptosis and cure abnormal atresia.

The development and maturation of follicles is a complex process which is regulated by gonadotropins and intraovarian regulators (Droge et al. 2008, Dierich et al. 1998). Particularly, follicle stimulating hormone (FSH) is required for the production of estrogen (Feng et al. 2017), growth and development of antral follicles (Bishop et al. 2017), and the selection of dominant follicles (DFs) (Fauser et al. 1997). These physiological responses to FSH are achieved by activating several signaling cascades in GCs, including protein kinase A (PKA), protein kinase $\mathrm{B}$ (PKB/AKT), p38 mitogenactivated protein kinase (p38-MAPK), and extracellular signal-regulated kinases 1 and 2 (ERK1/2), which modulate more than 100 target genes (Hunzicker et al. 2006). FSH was identified as one of the major survival factors for antral follicles for its ability to antagonize apoptosis in GCs (Chun et al. 1996, ). However, its target genes and the exact mechanism for protection of granulose cells from apoptosis remains to be understood

Excessive generation of ROS by external stimuli can activate many apoptotic pathways, such as PI3K/AKT, c-Jun N-terminal kinase (JNK), mitogenactivated protein kinase, and nuclear factor- $\mathrm{\kappa B}$ signaling (Simon et al. 2000, Finkel et al. 2000, Ki et al. 2013, Deng et al. 2017). Endoplasmic reticulum stress induced by adenosine triphosphate deficiency could lead to the generation of ROS and upregulate mRNA and protein expression of PUMA in neuronal cells (Steckley et al. 2007). However, apoptotic signaling pathways are often tissue specific and respond to condition specific triggers. Few studies have systematically demonstrated the involvement and function of PUMA in the progression of oxidative stress-induced GCs apoptosis.

In our previous study, PUMA was shown to play a pivotal role in oxidative stress-induced GC apoptosis, which was regulated by forkhead box protein $\mathrm{O} 1$ (FOXO1) transcription factors. However, it is unknown whether PUMA is regulated by FSH during oxidative stress-induced GCs apoptosis. In our present study, we investigated whether PUMA is regulated by FSH through examining PUMA mRNA expression and protein level in vivo as well as in vitro. Additionally, we investigated the role of PI3K/AKT pathway on the inhibition of PUMA by FSH.

\section{Methods}

\section{Ethical approval}

All animal procedures were approved by the Institutional Animal Care and Use Committee of Nanjing Agricultural University. The protocols were reviewed and approved, and the project number 2011CB100802 was assigned. The slaughter and sampling procedures strictly followed the 'Guidelines on Ethical Treatment of Experimental Animals' (2006) no. 398 established by the Ministry of Science and Technology, China and the 'Regulation regarding the Management and Treatment of Experimental Animals' (2008) no. 45 set by the Jiangsu Provincial People's Government.

\section{Animal and experimental procedures - In vivo study}

Three to 4-week-old female (Imprinting control region) ICR mice (Nanjing Qinglongshan Experimental Animal Center) were housed ( $\mathrm{n}=8$ per group), five per cage, in a temperature controlled $\left(22 \pm 2{ }^{\circ} \mathrm{C}\right)$ room with a 12: $12 \mathrm{~h}$ light: dark cycle (lights on from 0700 to 1900 hours) and free access to water and food. The control group, which received an equal volume of phosphatebuffered saline (PBS, pH 7.4, Sigma, St Louis, Missouri), the 3NP group, which was treated with $12 \mathrm{mg} / \mathrm{kg}$ 3-nitropropionic acid (3-NP) diluted with PBS twice daily for 1 week. the FSH group, which was treated with murine-FSH (Ningbo Second Hormone Factory, Ningbo, China) twice daily for 2 days at a dose of $10 \mathrm{IU}$ on day 1 and 5 IU on day 2 , the $3 \mathrm{NP} / \mathrm{FSH}$ group, which was 
treated with twice daily for 2 days at a dose of 10 IU on day 1 and 5 IU on day 2 and $12 \mathrm{mg} / \mathrm{kg} \mathrm{3-NP}$ diluted with PBS twice daily for 1 week. Mouse GCs were isolated from dominant follicles (DFs, $>200 \mu \mathrm{m}$ ) in the left ovaries of each mouse, for qRT-PCR. The right ovaries were fixed with $4 \%$ paraformaldehyde and embedded in paraffin for subsequent immunohistology.

\section{Animal and experimental procedures - In vitro study}

For primary MGC culture, the procedures were performed as described.4 In brief, 3- to 4-week-old Kun Ming mice were injected i.p. with 10 IU pregnant mare serum gonadotropin and killed $48 \mathrm{~h}$ later. 63 Superovulated mouse ovaries were harvested and individually transferred into $35-\mathrm{mm}$ Petri dishes containing $\mathrm{PBS}$ and then punctured with a syringe to release MGCs from DFs ( $>200 \mu \mathrm{m}$ in diameter) under a surgical dissecting microscope. The cell suspensions were plated in DMEM/F-12 (1:1) (Invitrogen, Shanghai, China) supplemented with $10 \%$ fetal bovine serum (FBS, Gibco, Grand Island, NY, USA) and 100 units/ml penicillin plus $100 \mu \mathrm{g} / \mathrm{ml}$ streptomycin (Gibco).

\section{Cell treatment}

After exposure to $200 \mu \mathrm{M} \quad \mathrm{H}_{2} \mathrm{O}_{2}$ (Sigma, St. Louis, MO, USA) for $1 \mathrm{~h}$, MGCs were rinsed with PBS and grown in serum-free DMEM/F-12 containing $7.5 \mathrm{IU} / \mathrm{ml} \mathrm{FSH} \mathrm{for} \mathrm{6h} \mathrm{(For} \mathrm{RT-PCR),} \mathrm{12h} \mathrm{(For} \mathrm{TUNEL}$ assay). In some experiments, LY294002 $(20 \mu \mathrm{M})$ was added $1 \mathrm{~h}$ before FSH treatment.

\section{TUNEL assay}

Terminal deoxynucleotide triphosphate transferase-mediated deoxyuridine triphosphate nick-end labeling (TUNEL) was accomplished using an insitu Cell Death Detection Kit (Roche, Switzerland) to detect cellular apoptosis, After TUNEL reactions, cell climbing sheets or ovarian sections were mounted with VECTASHIELD Mounting Medium and examined under a laser-scanning confocal microscope (Carl Zeiss)

Determination of Bim, caspase-3, Puma mRNA levels by $R T-P C R$

Total RNA was isolated from the treated GCs using Trizol reagent (Invitrogen, USA) according to the manufacturer's instructions. The quantity and purity of the RNA were determined by measuring the ratio of absorbance at 260/280 nm using a NanoDrop 2000 spectrophotometer (Thermo Fisher Scientific Inc., USA). The total RNA $(1 \mu \mathrm{g})$ was then reverse transcribed by adding $5 \times$ gDNA Eraser Buffer and gDNA Eraser, and incubating at $42{ }^{\circ} \mathrm{C}$ for $2 \mathrm{~min}$. PrimeScript RT Enzyme Mix I, RT Primer Mix and $5 \times$ PrimeScript Buffer were subsequently added, and the mixture was incubated at $37^{\circ} \mathrm{C}$ for $10 \mathrm{~min}$. The samples were then heated at $85^{\circ} \mathrm{C}$ for $5 \mathrm{~s}$ to inactivate the enzymes, and stored at $20^{\circ} \mathrm{C}$. A Rotor Gene-3000 PCR machine (Gene Co., Hong Kong) and a real-time PCR kit (SYBR ${ }^{\circledR}$ Premix Ex TaqTM II) were used according to the manufacturer's instructions. The primers used for the target genes and $\beta$-Actin (synthesized by Shanghai Generay Biotech Co., Ltd) are shown in Table 1.

Table 1. Primer sequences used for $q R T-P C R$ analysis of target genes.

\begin{tabular}{ll}
\hline Target genes & Primer sequences (5'-3') \\
\hline PUMA & ATGGCGGACGACCTCAAC \\
& AGTCCCATGAAGAGATTGTACATGAC \\
Bim & TATGGAGAAGGCATTGAC \\
& TGTGGTGATGAACAGAGG \\
Caspase-3 & ACAGCACCTGGTTACTATTC \\
& CAGTTCTTTCGTGAGCAT \\
$\beta$-Actin & GCTGTCCCTGTATGCCTCT \\
& GTCTTTACGGATGTCAACG \\
\hline
\end{tabular}

\section{Statistical analysis}

Data are presented as the means \pm SEM. Data were tested for normal distribution, and statistical significance was assessed by the independent sample t-test using SPSS version 11.0 for Windows (SPSS Inc., Chicago, IL, USA). Data were considered statistically significant if $\mathrm{P}<0.05$.

\section{Results}

\section{FSH protected GCs from apoptosis in vivo}

As shown in Fig. 1, the 3NP-treated group had significantly increased apoptosis rate compared to the control group $(\mathrm{P}<0.05)$. Compared with the $3 \mathrm{NP}$-treated group, the FSH-treated group had significantly decreased apoptosis rate $(\mathrm{P}<0.05)$. Compared with the FSH-treated group, 3NP treatment significantly inhibited the decrease of apoptosis rate $(\mathrm{P}<0.05)$.

\section{FSH reduced PUMA expression in GCs}

As shown in Fig. 2, the 3NP-treated group had significantly increased the mRNA levels of puma compared to the control group $(\mathrm{P}<0.05)$. Compared with the 3NP-treated group, the FSH-treated group had significantly decreased the mRNA levels of bim, caspase- 
3 and puma $(\mathrm{P}<0.05)$. Compared with the FSH-treated group, 3NP treatment significantly inhibited the decrease of puma mRNA levels $(\mathrm{P}<0.05)$.

\section{FSH protected GCs from apoptosis in vitro}

The $\mathrm{H}_{2} \mathrm{O}_{2}$-treated group had significantly increased apoptosis rate compared to the control group $(\mathrm{P}<0.05)$. Compared with the $\mathrm{H}_{2} \mathrm{O}_{2}$-treated group, the FSH-treated group had significantly decreased apoptosis rate $(\mathrm{P}<0.05)$. Compared with the FSH-treated group, $\mathrm{H}_{2} \mathrm{O}_{2}$ treatment significantly inhibited the decrease of apoptosis rate $(\mathrm{P}<0.05)$ (Fig. 3).
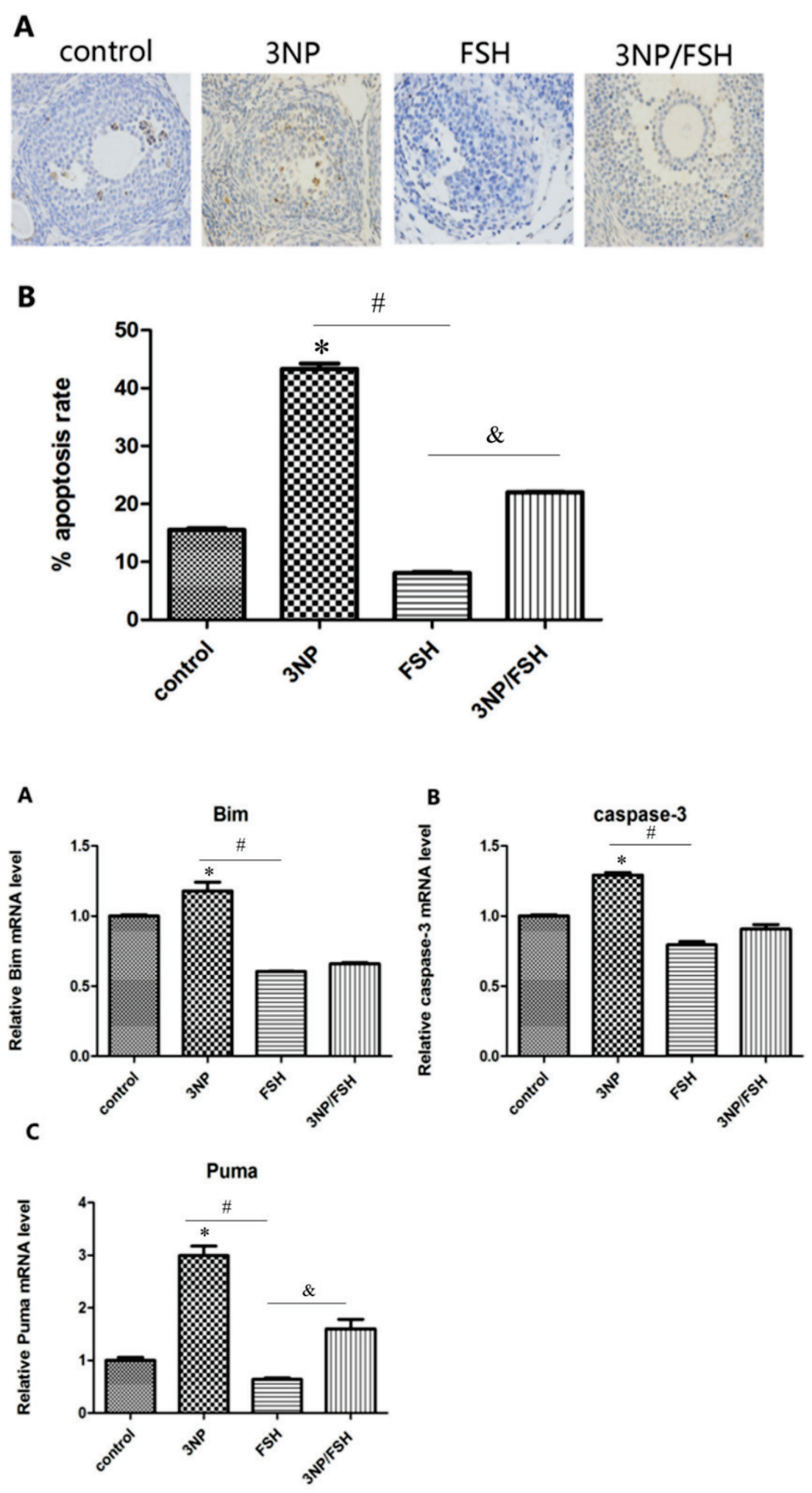

Fig. 1. FSH protected MGCs from apoptosis in vivo.

Data are presented as the means \pm SEM, $\mathrm{n}=3 .{ }^{*} \mathrm{P}<0.05$ compared with control group, ${ }^{\#} \mathrm{P}<0.05$ compared to the 3NP-treated group, ${ }^{\&} \mathrm{P}<0.05$ compared to the FSH-treated group.

Fig. 2. FSH reduced PUMA expression in ovarian granulosa cell.

(A) mRNA levels of Bim. (B) mRNA levels of caspase-3. (C) mRNA levels of Puma. Data are presented as the means \pm SEM, $n=3$. $* \mathrm{P}<0.05$ compared with control group, ${ }^{\#} \mathrm{P}<0.05$ compared to the 3NP-treated group, ${ }^{\&} \mathrm{P}<0.05$ compared to the $\mathrm{FSH}-$ treated group. 


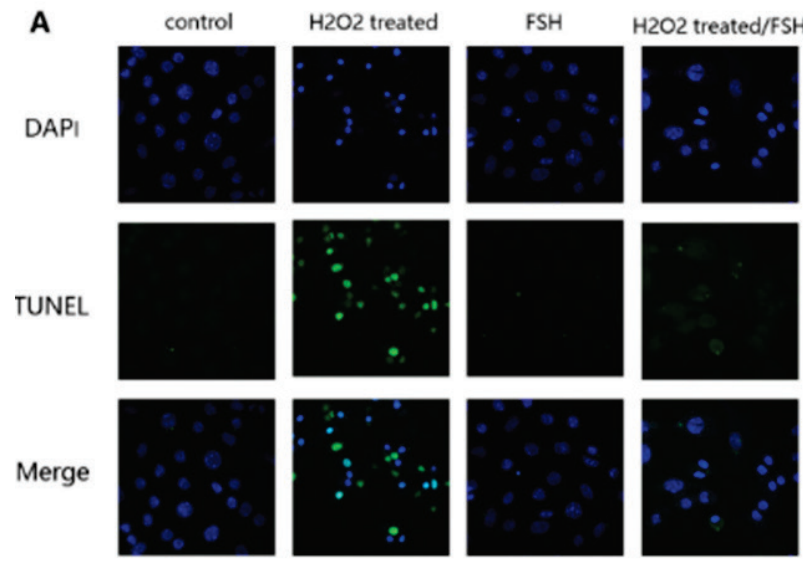

B

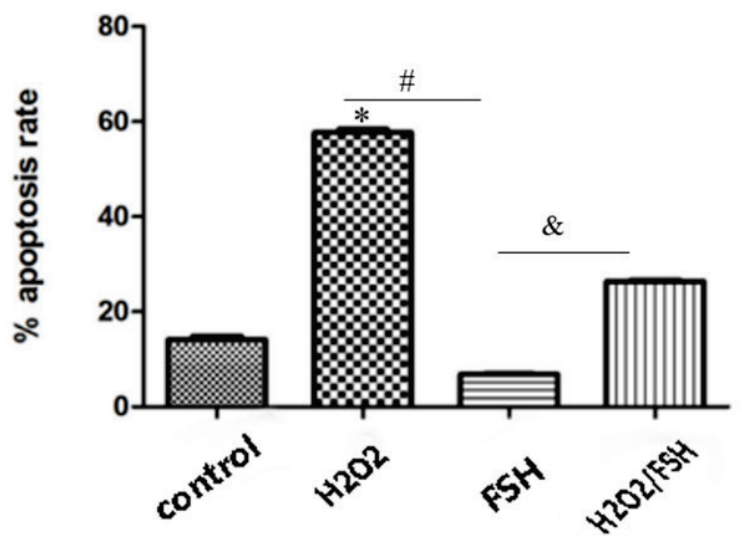

Fig. 3. FSH protected granulosa cell from apoptosis in vivo.

Data are presented as the means \pm SEM, $n=3$. $* \mathrm{p}<0.05$ compared with control group, ${ }^{\#} \mathrm{P}<0.05$ compared to the $\mathrm{H}_{2} \mathrm{O}_{2}$-treated group, ${ }^{\&} \mathrm{P}<0.05$ compared to the $\mathrm{FSH}$-treated group.

\section{FSH attenuated PUMA expression in GCs}

As shown in Fig. 4, the $\mathrm{H}_{2} \mathrm{O}_{2}$-treated group had significantly increased the mRNA levels of puma compared to the control group $(\mathrm{P}<0.05)$. Compared with the $\mathrm{H}_{2} \mathrm{O}_{2}$-treated group, the FSH-treated group had significantly decreased the mRNA levels of Bim, caspase-3, puma $(\mathrm{P}<0.05)$. Compared with the FSH-treated group, $\mathrm{H}_{2} \mathrm{O}_{2}$ treatment significantly inhibited the decrease of puma mRNA levels $(\mathrm{P}<0.05)$.

FSH reduced PUMA expression in a PI3K-AKTdependent manner

As shown in Fig. 5, the $\mathrm{H}_{2} \mathrm{O}_{2}$-treated group had significantly increased the mRNA levels of Puma compared to the control group $(\mathrm{P}<0.05)$. Compared with the $\mathrm{H}_{2} \mathrm{O}_{2}$-treated group, the $\mathrm{H}_{2} \mathrm{O}_{2} / \mathrm{FSH}$-treated group had significantly decreased the mRNA levels of Bim, caspase-3 and puma $(\mathrm{P}<0.05)$. Compared with the $\mathrm{H}_{2} \mathrm{O}_{2} /$ FSH-treated group, LY294002 (PI3K inhibitor) treatment significantly inhibited the decrease of puma mRNA levels $(\mathrm{P}<0.05)$.
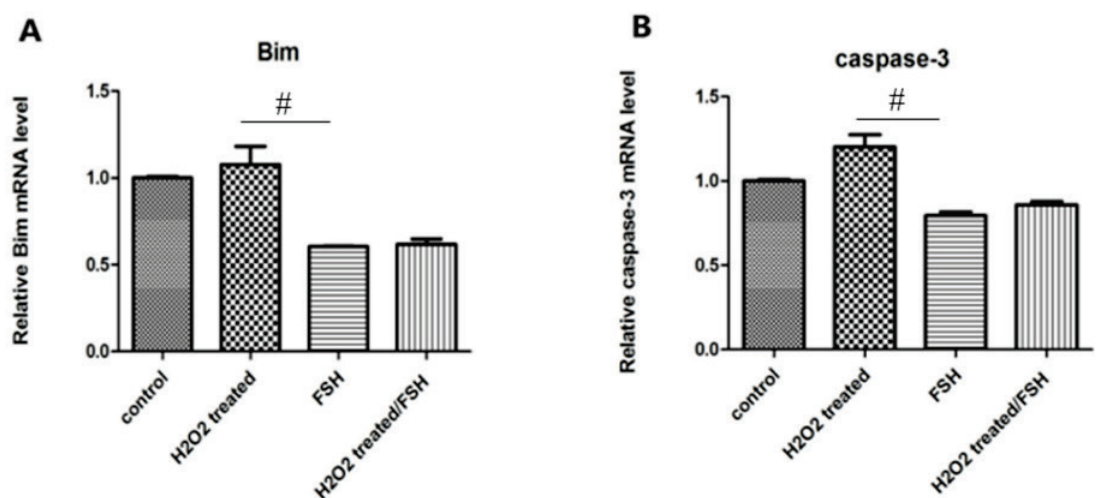

Fig. 4. FSH attenuated PUMA expression in granulosa cell.

(A) mRNA levels of Bim. (B) mRNA levels of caspase-3. (C) mRNA levels of Puma. Data are presented as the means $\pm S E M, n=3$. $* \mathrm{P}<0.05$ compared with control group, ${ }^{\#} \mathrm{P}<0.05$ compared to the $\mathrm{H}_{2} \mathrm{O}_{2}$-treated group, ${ }^{\&} \mathrm{P}<0.05$ compared to the FSHtreated group.

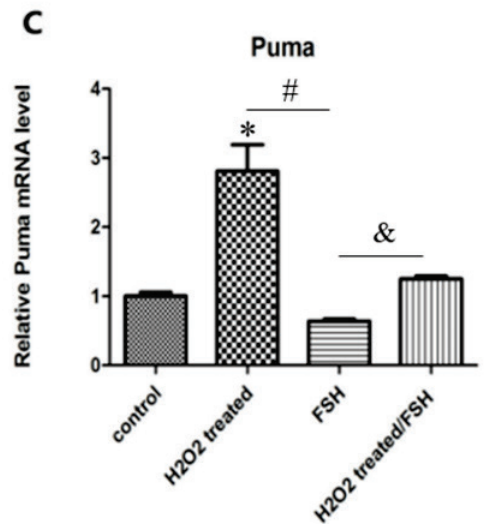




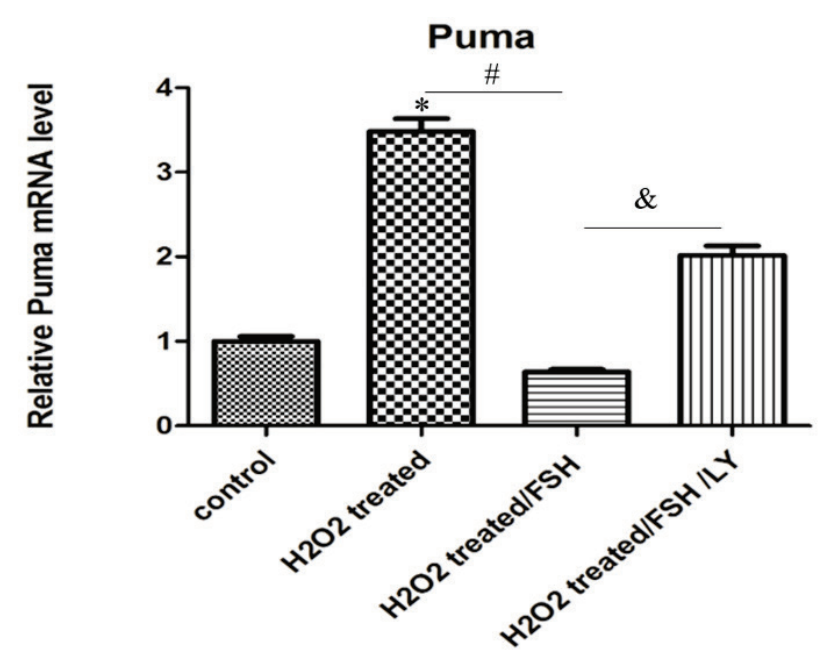

Fig. 5. FSH reduced PUMA expression in a PI3K-AKT-dependent manner. Data are presented as the means \pm SEM, $n=3$. $* P<0.05$ compared with control group, ${ }^{\#} \mathrm{P}<0.05$ compared to the $\mathrm{H}_{2} \mathrm{O}_{2}$-treated group, ${ }^{\&} \mathrm{P}<0.05$ compared to the $\mathrm{H}_{2} \mathrm{O}_{2} / F S H / L Y-$ treated group.

\section{Discussion}

The demand for oxygen increases during follicular development, which can easily shift the redox balance of GCs and increase the ROS content, causing subsequent apoptosis and follicular atresia (Agarwal et al. 2005). Therefore, identifying the factors that inhibit the oxidative stress and apoptosis in ovarian GCs will serve to enrich our understanding of follicular development and have a great impact on our practice. Ovarian cell apoptosis can lead to follicular atresia and luteal dissolution, and in the process of cell apoptosis, it is regulated by a series of proteins related to apoptosis, genes and expression products, such as the anti-apoptotic protein Bcl-2 family and the homologous pro-apoptotic protein Bax, which play an important role in the process of apoptosis (Šedová et al. 2018). In particular, we investigated the role of FSH and PUMA in GCs apoptotic processes related to follicular atresia in mouse ovaries under in vitro as well as in vivo conditions. Taken together, our results demonstrated that FSH could downregulate the PUMA expression induced by oxidative stress in vivo as well as in vitro.

Our previous study demonstrated that ROS can induce PUMA expression in GCs, and showed that one of the upstream PUMA is FOXO1 (Liu et al. 2015). Here we tried to demonstrate weather there are any factors that are responsible for inhibiting the ROS induced apoptosis in GCs, and which pathway the factors follow to downregulate the expression of PUMA. Gonadotrophins
(FSH and luteinizinghormone) are primarily responsible for the selection of dominant follicles (Mihm et al. 2008, Popelová et al. 2018). FSH could promote antral follicle growth and development into pre-ovulatory follicles, which will maintain anovulation without stimulation by luteinizinghormone (Maillet et al. 2005). FSH withdrawal (coasting) during this stage leads to GCs apoptosis and follicular atresia.

Two major cascades lead to apoptosis: the extrinsic pathway (type I cell death pathway), which activates cell surface receptors in response to external signals such as fas ligand, and the intrinsic pathway (type II cell death pathway), which causes cytochrome c release into the cytosol following mitochondrial membrane disruption that is induced by Bcl-2 family members. Previous studies identified Bim as a BH3-only protein that promotes apoptosis by changing the balance between pro- and anti-apoptotic members of the Bcl-2 family, thereby affecting permeability of the mitochondrial membrane to cytochrome $\mathrm{c}$, which further triggers the activation of caspase-9, caspase-3 and the cell death program (Shen et al. 2014). GCs apoptosis driven by FSH withdrawal induced hallmarks of mitochondrial apoptosis (Bim, caspase-9 and caspase-3), which were then suppressed in the presence of FSH. In this study, we found that the FSH-treated group had significantly decreased the mRNA levels of bim, caspase- 3 and puma compared to the 3NP-treated group in vivo. 3NP significantly induced cells apoptosis, however, FSH treatment significantly decreased the apoptosis rate in 3NP-induced GCs. This result indicated that FSH can protect against 3NP-induced apoptosis in GCs.

Previously, we found that oxidative stress induced by $3 \mathrm{NP}$ injection in mice increases PUMA mRNA expression. In consistence with the in vivo experiment, our in vitro experiment showed that FSH could downregulate the PUMA mRNA expression. However, the level of PUMA expression in FSH treated GCs with 3NP treatment was still higher than that of in control GCs. As many BH3-only Bcl-2 subfamily proteins have similar effects on cellular apoptosis, it is possible that oxidative stress-induced apoptotic signaling was regulated by other $\mathrm{BH} 3$-only domain proteins after FSH treatment.

To further validate our hypothesis, that FSH could inhibit the PUMA expression to downregulate apoptosis induced by ROS. In this study, we found that $\mathrm{H}_{2} \mathrm{O}_{2}$ significantly induced cells apoptosis in vitro, however, FSH treatment significantly decreased the 
apoptosis rate in $\mathrm{H}_{2} \mathrm{O}_{2}$-induced GCs. This result indicated that FSH can protect against $\mathrm{H}_{2} \mathrm{O}_{2}$-induced apoptosis in GCs.

Moreover, the result demonstrated that FSH could downregulate the PUMA expression at mRNA level, through in vivo and in vitro experiments, we showed that FSH could downregulate the PUMA expression at mRNA level to inhibit the apoptosis induced by $\mathrm{H}_{2} \mathrm{O}_{2}$.

The above experiments indicate that FSH could regulate the PUMA expression to inhibit the oxidative stress induced apoptosis, FSH regulates the growth and differentiation of follicular GCs through several downstream signaling pathways, including PKA, PI3K, AKT p38-MAPK and ERK1/2 although their interactions in response to FSH remain to be investigated (HunzickerDunn et al. 2006). Our lab had previously demonstrated that FSH could regulate the FOXO expression to inhibit the oxidative stress induced apoptosis (Liu et al. 2015).
We demonstrated that LY294002 (PI3K inhibitor) abolished the downregulation of PUMA mRNA by FSH in vitro. Therefore, our data raised the possibility that FSH prevents PUMA expression from undergoing apoptosis in a PI3K/AKT-dependent manner.

In conclusion, we demonstrated that FSH could downregulate PUMA mRNA expression to inhibit the ROS induced apoptosis in vivo and in vitro experiments and this process is through PI3K/AKT pathway.

\section{Conflict of Interest}

There is no conflict of interest.

\section{Acknowledgements}

This work was supported by the following two Projects: 1) Chinese National Programs for Fundamental Research and Development (973 program no. 2014CB138502).

2) Qinglan Project of JiangSu Province (2018).

\section{References}

ASSELIN E, XIAO CW, WANG YF, TSANG BK: Mammalian follicular development and atresia: role of apoptosis. Neurosignals 9: 87-95, 2000. https://doi.org/10.1159/000014627

BISHOP LA, RICHTER KS, PATOUNAKIS G, ANDRIANI L, MOON K, DEVINE K: Diminished ovarian reserve as measured by means of baseline follicle-stimulating hormone and antral follicle count is not associated with pregnancy loss in younger in vitro fertilization patients. Fertil Steril 108: 980-987, 2017. https://doi.org/10.1016/i.fertnstert.2017.09.011

CHUN SY, EISENHAUER KM, MINAMI S, BILLIG H, PERLAS E, HSUEH AJ: Hormonal regulation of apoptosis in early antral follicles: follicle-stimulating hormone as a major survival factor. Endocrinology 137: $1447-$ 1456, 1996. https://doi.org/10.1210/endo.137.4.8625923

DENG H, KUANG P, CUI H, LUO Q, LIU H, LU YJ, FANG J, ZHAO L: Sodium fluoride induces apoptosis in mouse splenocytes by activating ROS-dependent NF- $\mathrm{B}$ signaling. Oncotarget 70: 114428-114441, 2017. https://doi.org/10.18632/oncotarget.22826

DROEGE W, KINSCHERF R: Aberrant insulin receptor signaling and amino acid homeostasis as a major cause of oxidative stress in aging. Antioxid Redox Signal 10: 661-678, 2008. https://doi.org/10.1089/ars.2007.1953

DIERICH A, SAIRAM MR, MONACO L, MARIA GF, CORSI PS: Impairing follicle-stimulating hormone (FSH) signaling in vivo: targeted disruption of the FSH receptor leads to aberrant gametogenesis and hormonal imbalance. P Natl Acad Sci 95: 13612-13617, 1998. https://doi.org/10.1073/pnas.95.23.13612

FENG Y, ZHU S, ANTARIS AL, CHEN H, XIAO YL, LU XW, JIANG LL, DIAO S, YU K, WANG Y, HSUEH AJ: Live imaging of follicle stimulating hormone receptors in gonads and bones using near infrared II fluorophore. Chem Sci 8: 3703-3711, 2017. https://doi.org/10.1039/C6SC04897H

FAUSER BC, VAN HEUSDEN AM: Manipulation of human ovarian function: physiological concepts and clinical consequences. Endocr Rev 18:71-106, 1997. https://doi.org/10.1210/edrv.18.1.0290

FINKEL T, HOLBROOK NJ: Oxidants, oxidative stress and the biology of ageing. Nature 408: 239-247, 2000. https://doi.org/10.1038/35041687

HUNZICKER DM, MAIZELS ET: FSH signaling pathways in immature granulosa cells that regulate target gene expression: branching out from protein kinase A. Cell Signal 18: 1351-1359, 2006. https://doi.org/10.1016/j.cellsig.2006.02.011 
HUNZICKER DM, MAIZELS ET: FSH signaling pathways in immature granulosa cells that regulate target gene expression: branching out from protein kinase A. Cell Signal 18: 1351-1359, 2006. https://doi.org/10.1016/j.cellsig.2006.02.011

INDRAJIT CHOWDHURY, WINSON E, THOMPSON, CRYSTAL WELCH, KELWYN THOMAS, ROLAND MATTHEWS: Prohibitin (PHB) inhibits apoptosis in rat granulosa cells (GCs) through the extracellular signalregulated kinase $1 / 2$ (ERK1/2) and the $\mathrm{Bcl}$ family of proteins. Apoptosis 18: 1513-1525, 2013. https://doi.org/10.1007/s10495-013-0901-z

JIN YI JIANG, CARMEN KM. CHEUNG, YI FANG WANG, BENJAMIN K, TSANG: Regulation of cell death and cell survival gene expression during ovarian follicular development and atresia. Front Bio Sci 8: 222-237, 2011. https://doi.org/10.2741/949

KI YW, PARK JH, LEE JE, SHIN IC, KOH HC: JNK and p38 MAPK regulate oxidative stress and the inflammatory response in chlorpyrifos-induced apoptosis. Toxicol Lett 218: 235-245, 2013. https://doi.org/10.1016/j.toxlet.2013.02.003

LIU ZQ, SHEN M, WU WJ: Expression of puma in follicular granulosa cells regulated by FoxO1 activation during oxidative stress. Reprod Sci 22: 696-705, 2015. https://doi.org/10.1177/1933719114556483

MIHM M, EVANS AC: Mechanisms for dominant follicle selection in monovulatory species: a comparison of morphological, endocrine and intraovarian events in cows, mares and women. Reprod Domest Anim 2: 48-56, 2008. https://doi.org/10.1111/j.1439-0531.2008.01142.x

MAILLET G, FERAL C, BENHAIM A: Apoptosis of the follicular cells: its implication in ovarian induction protocols. Gynecol Obstet Fertil 33: 653-658, 2005. https://doi.org/10.1016/j.gyobfe.2005.06.016

POPELOVÁ A, KÁKONOVÁ A, HRUBÁ L, KUNEŠ J, MALETÍNSKÁ L, ŽELEZNÁ B: Potential neuroprotective and anti-apoptotic properties of a long-lasting stable analog of ghrelin: an in vitro study using SH-SY5Y cells. Physiol Res 67: 339-346, 2018. https://doi.org/10.33549/physiolres.933761

ROYCHOUDHURY S, NATH S, MASSANYI P, STAWARZ R, KACANIOVA M, KOLESAROVA A. Copperinduced changes in reproductive functions: in vivo and in vitro effects. Physiol Res 65: 11-22, 2016. https://doi.org/10.33549/physiolres.933063

SHEN M, CAO Y, JIANG Y, WEI YH, LIU HL: Melatonin protects mouse granulosa cells against oxidative damage by inhibiting FOXO1-mediated autophagy: Implication of an antioxidation-independent mechanism. Redox biology 18: 138-157, 2018. https://doi.org/10.1016/j.redox.2018.07.004

SIMON HU, HAJ YA, LEVI SF: Role of reactive oxygen species (ROS) in apoptosis induction. Apoptosis 5: 415-418, 2000. https://doi.org/10.1023/A:1009616228304

STECKLEY D, KARAJGILAR M, DALE LB, FUERTH B, SWAN P: Puma is a dominant regulator of oxidative stress induced Bax activation and neuronal apoptosis. J Neuro Sci 27: 12989-12999, 2007. https://doi.org/10.1523/JNEUROSCI.3400-07.2007

ŠEDOVÁ L, ŠKOLNÍKOVÁ E, HODÚLOVÁ M, VČELÁK J, ŠEDA O, BENDLOVÁ B: Expression profiling of Nme7 interactome in experimental models of metabolic syndrome. Physiol Res 67 (Suppl 3): S543-S550, 2018. https://doi.org/10.33549/physiolres. 934021

SHEN M, LIU Z, LI B, TENG Y, ZHANG J, TANG Y, LIU H: Involvement of FoxO1 in the effects of folliclestimulating hormone on inhibition of apoptosis in mouse granulosa cells. Cell Death Dis 5: e1475-e1475, 2014. https://doi.org/10.1038/cddis.2014.400

YANG H, XIE Y, YANG D, REN D: Oxidative stress-induced apoptosis in granulosa cells involves JNK, p53 and Puma. Oncotarget 8: 25310, 2017. https://doi.org/10.18632/oncotarget.15813

VALDEZ, KELLI E S, PEDER CUNEO, ADELE M, TURZILLO: Regulation of apoptosis in the atresia of dominant bovine follicles of the first follicular wave following ovulation. Reproduction 130: 71-81, 2005. https://doi.org/10.1530/rep.1.00430 